\title{
Article \\ Multiple Allergen Simultaneous Test-Immunoblot Assay for Immunoglobulin E Detection in Patients with Isolated Allergic Conjunctivitis
}

\author{
Jung Yeob Han ${ }^{1,+} \oplus$, Hun Lee ${ }^{1,+} \oplus$, Jae Lim Chung ${ }^{2} \mathbb{C}$, Young Jun Kim ${ }^{2}$, Jae Yong Kim ${ }^{1, *}$ and Hungwon Tchah ${ }^{1, *}$ \\ 1 Department of Ophthalmology, Asan Medical Center, University of Ulsan College of Medicine, \\ Seoul 05505, Korea; dryeob@gmail.com (J.Y.H.); yhun777@gmail.com (H.L.) \\ 2 Eyejun Ophthalmic Clinic, Seoul 06232, Korea; jaelim.chung@gmail.com (J.L.C.); einsjun@hanmail.net (Y.J.K.) \\ * Correspondence: jykim2311@amc.seoul.kr (J.Y.K.); hwtchah@amc.seoul.kr (H.T.) \\ + The first two authors contributed equally to this study.
}

check for updates

Citation: Han, J.Y.; Lee, H.; Chung, J.L.; Kim, Y.J.; Kim, J.Y.; Tchah, H. Multiple Allergen Simultaneous Test-Immunoblot Assay for Immunoglobulin E Detection in Patients with Isolated Allergic Conjunctivitis. J. Clin. Med. 2021, 10, 960. https://doi.org/10.3390/ jcm10050960

Academic Editors: Emmanuel Andrès and Yoko Ozawa

Received: 16 January 2021

Accepted: 19 February 2021

Published: 1 March 2021

Publisher's Note: MDPI stays neutral with regard to jurisdictional claims in published maps and institutional affiliations.

Copyright: (c) 2021 by the authors. Licensee MDPI, Basel, Switzerland. This article is an open access article distributed under the terms and conditions of the Creative Commons Attribution (CC BY) license (https:// creativecommons.org/licenses/by/ $4.0 /)$.

\begin{abstract}
We aimed to investigate the immunoglobulin E (IgE) detection rate and allergen patterns in patients with isolated allergic conjunctivitis using the multiple allergen simultaneous test (MAST)immunoblot assay. A total of 120 patients with allergic conjunctivitis and no associated rhinitis, asthma, or dermatitis underwent the MAST-immunoblot assay to measure serum total $\operatorname{IgE}(\mathrm{TIgE})$ and serum specific IgE (SIgE) against 57 allergens. Patients were classified into subgroups based on the season when the eye symptoms were exacerbated, and TIgE and SIgE positivity. Differences between sex and age groups were also analyzed. Of the 120 patients, 57.5\% (69 patients) and 69.2\% (83 patients) were positive for $\operatorname{TIgE}(\geq 100 \mathrm{IU} / \mathrm{mL})$ and $\operatorname{SIgE}(\geq 0.7 \mathrm{IU} / \mathrm{mL})$, respectively. The allergens that most frequently triggered sensitization in the study population were Dermatophagoides farinae, Dermatophagoides pteronyssinus, Tyrophagus putrescentiae, Alternaria, and house dust. House dust mites, such as D. farinae and D. pteronyssinus, showed the highest detection rates regardless of the season. Men had a higher positive rate for TIgE than women, whereas a higher rate of sensitization, detected as SIgE positivity, was seen in younger patients. In conclusion, MAST-immunoblot assay can detect sensitizing allergens in patients with isolated allergic conjunctivitis.
\end{abstract}

Keywords: allergic conjunctivitis; multiple allergen simultaneous test-immunoblot assay; serum immunoglobulin E

\section{Introduction}

Allergy is defined as type I hypersensitivity reaction to certain substances known as allergens (e.g., environmental factors, food, and drugs) [1]. Approximately 15-20\% of the world's population develops a form of allergic disease, of which $40-60 \%$ of individuals are estimated to present ocular allergic symptoms [2]. Although ocular allergies are generally recognized as a disease accompanying allergic rhinitis, and many studies have been conducted on allergic rhinoconjunctivitis, isolated ocular allergies remain underestimated and are increasingly being recognized as an important independent disease [3]. In addition, ocular allergies are considered a major public health concern, leading to lower productivity and education efficiency [4].

Allergic diseases are usually diagnosed based on the clinical history and characteristic signs and symptoms; however, measuring immunoglobulin E ( $\operatorname{IgE}$ ) levels using in vivo or in vitro methods is performed to detect sensitization [5]. IgE plays an important role in the pathogenesis of allergy, and various methods of detecting IgE have been the subject of research [6]. Allergic reaction occurs in two pathophysiological steps. An initial sensitization phase is characterized by exposure to an allergen that is recognized by serum specific $\operatorname{IgE}$ (SIgE) antibodies on the mast cells or basophils. In the second phase, further exposure to allergens induces the degranulation of mast cells or basophils, leading to the secretion of 
inflammatory mediators, cytokines, chemokines, and eicosanoids [7]. This process causes several systemic or localized effects, such as vasodilation, smooth muscle contraction, mucous production, and tissue eosinophilic infiltration [8]. In vivo tests include the skin prick test (SPT), intradermal test, and nasal or conjunctival provocation test, whereas in vitro tests involve measurement of serum total immunoglobulin E (TIgE) and serum-specific immunoglobulin E (SIgE) levels (e.g., the fluoroallergosorbent test (FAST), ImmunoCAP (Phadia AB, Uppsala, Sweden), Immulite (Siemens Healthcare Diagnostics, Tarrytown, NY, USA), and multiple allergen simultaneous test (MAST)) $[9,10]$.

Although SPT is commonly performed in clinics, there are several limitations in terms of a patient's comfort, and the results may be affected by skin conditions or medications [11-14]. In contrast, in vitro tests for detecting IgE in the serum are independent of the effects of medications or skin disease [15]. Furthermore, quantitative results have the advantage of reduced subjectivity or operator error [16]. Among several in vitro test methods, the multiple allergen simultaneous test (MAST) is more widely used because it involves a simpler and faster procedure. MAST-immunoblot assay is the most recently developed method, and many studies are being conducted on it targeting allergic patients [9,17-19]. In addition, MAST has the advantage of being able to test many allergens at once.

However, only a few studies have investigated the allergen pattern in isolated seasonal or perennial allergic conjunctivitis patients using the MAST-immunoblot assay. Therefore, the purpose of this study is to analyze the results of the MAST-immunoblot assay in patients with isolated allergic conjunctivitis. Furthermore, through subgroup analysis, we investigated the correlation between IgE detection rate and season, sex, and age.

\section{Materials and Methods}

This study was conducted with the approval of the Institutional Review Board of the Asan Medical Center and University of Ulsan College of Medicine, Seoul, Korea (2020-1858). The study adhered to the tenets of the Declaration of Helsinki and followed the Good Clinical Practice guidelines. A retrospective chart review was performed for patients who underwent a MAST-immunoblot assay and had a diagnosis of allergic conjunctivitis.

\subsection{Patient Enrollment}

Allergic conjunctivitis was diagnosed using the following criteria: (1) clinical symptoms of ocular itching with hyperemia, foreign body sensation, ocular pain, and secretion of white mucus with or without seasonal variation; and (2) specific allergic conjunctivitis signs seen on slit lamp examination, including conjunctival hyperemia, conjunctival edema, and conjunctival follicle or papillary hypertrophy [20]. Patients were excluded from analysis using the following criteria: (1) diagnosed with IgE and non-IgE mediated ocular allergy (vernal keratoconjunctivitis and atopic keratoconjunctivitis) or non-IgE mediated ocular allergy (giant papillary conjunctivitis, contact keratoconjunctivitis); (2) allergic symptoms other than those involving the eye, such as rhinitis, dermatitis, and asthma; and (3) comorbid conditions that could affect serum IgE levels, such as infectious diseases caused by Mycoplasma pneumoniae, Campylobacter jejuni, Candida, helminth, and human immunodeficiency virus; neoplastic diseases; pregnancy; or postpartum conditions.

\subsection{MAST-Immunoblot Assay}

All patients underwent the MAST-immunoblot assay using the AdvanSure AlloStation Smart II (AS: LG Life Science, Seoul, Korea). Testing was performed according to the manufacturer's recommendations. Briefly, $50 \mu \mathrm{L}$ of each patient's serum was pipetted into a reaction chamber containing the allergens on a nitrocellulose membrane and incubated at room temperature for $45 \mathrm{~min}$. After washing, mouse anti-human IgE antibody coupled with biotin was added and incubated at room temperature for $30 \mathrm{~min}$. Anti-human IgE antibody coupled with biotin acted as a secondary antibody, catalyzing the transformation of a specific substrate with a distinguishable property. After washing to remove the unbound antibodies, $250 \mathrm{~mL}$ of streptavidin conjugated to alkaline phosphatase was added 
and incubated at room temperature for $20 \mathrm{~min}$. Non-bound conjugate was removed by washing. After adding the color-formation solution and incubating at room temperature for $20 \mathrm{~min}$, test strips were completely dried. The result was converted into $\mathrm{IU} / \mathrm{mL}$ through the formula for each antigen built into the program, which was measured according to the color intensity of the band (Figure 1).
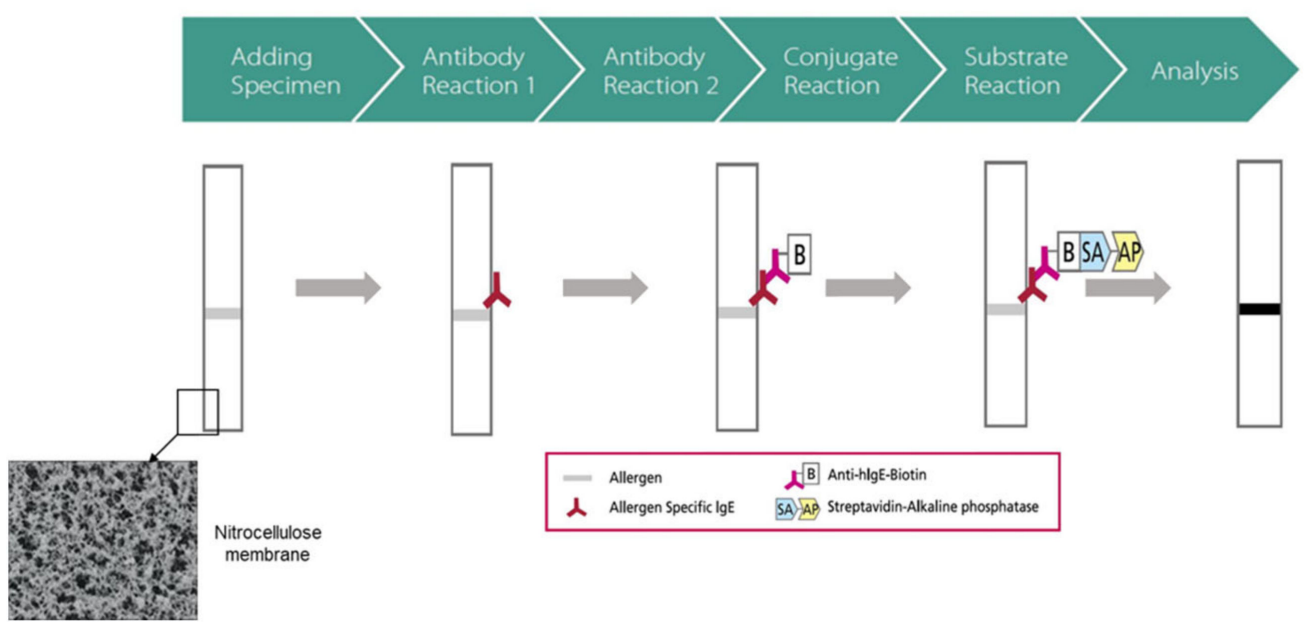

Figure 1. Schematic explanation of the measurement principle of the multiple allergen simultaneous test-immunoblot assay (AdvanSure AlloStation Smart II).

MAST-immunoblot assay results were obtained for TIgE and SIgE for 57 allergens. TIgE was classified into positive and negative, using $100 \mathrm{IU} / \mathrm{mL}$ as a cut-off. If the TIgE concentration was more than $100 \mathrm{IU} / \mathrm{mL}$, patients were included in the TIgE+ group. In this study, allergens with a SIgE concentration of $0.7 \mathrm{IU} / \mathrm{mL}$ or above were considered positive.

The patients were then classified based on the season when the eye symptoms were exacerbated: spring (March to May), summer (June to August), fall (September to November), and winter (December to February). The results for TIgE and SIgE positivity were classified into four groups according to the MAST-immunoblot assay results: Group 1 (TIgE+, SIgE+), Group 2 (TIgE-, SIgE+), Group $3(\mathrm{TIgE}+, \mathrm{SIgE}-)$, and Group 4 (TIgE-, SIgE-). In addition, differences in the positivity of TIgE and SIgE between sex and age groups were also analyzed. Regarding age groups, patients were divided into young and old groups ( $\leq 35$ years and $\geq 35$ years). The rationale for the baseline of 35 years is based on a previous study in which serum IgE levels peaked in the late 20s (28-30 years old) and then showed declining patterns from the late 30s (36-40 years old) [21].

\subsection{Statistical Analysis}

All statistical analyses were performed using SPSS statistical software (version 25.0, IBM Corp., Armonk, NY, USA) and statistical significance was defined as $p<0.05$. The comparison of subgroup variables classified by season when the eye symptoms were exacerbated and by IgE positivity was performed using the non-parametric Kruskal-Wallis test, Pearson's chi-square test, and Fisher's exact test. Comparison by sex and age groups was performed with the non-parametric Mann-Whitney U test and Pearson's chi-square test.

\section{Results}

\subsection{Demographic Data}

A total of 120 patients (32 men, 88 women) with an average age of $35.7 \pm 17.5$ years (range, 4-78 years) were included in this study. When divided by season of exacerbating symptoms, 29, 49,32, and 10 patients were included in the spring, summer, fall, and winter groups, respectively. 


\subsection{MAST-Immunoblot Assay (Overall)}

The allergens that were most frequently detected through MAST in the total study population were Dermatophagoides farinae (36.7\%), Dermatophagoides pteronyssinus (34.2\%), Tyrophagus putrescentiae (17.5\%), Alternaria (15.8\%), and house dust (14.2\%) (Table 1). House dust mites, such as $D$. farinae and D. pteronyssinus showed the highest detection rates regardless of the season; however, other allergens showed differences according to the season (spring: house dust, Acarus siro, and rye pollen; summer: Alternaria, T. putrescentiae, and house dust; fall: Mugwort, T. putrescentiae, ragweed, oxeye daisy, Japanese hop, and dandelion; and winter: Alternaria, house dust, cat, oxeye daisy, and Cladosporium (Table 1)).

Table 1. Positive rate of each allergen-specific immunoglobulin E (IgE) detected by multiple allergen simultaneous testimmunoblot assay subdivided by seasons.

\begin{tabular}{|c|c|c|c|c|c|}
\hline Allergen & $\begin{array}{c}\text { Total } \\
(100 \%, n=120)\end{array}$ & $\begin{array}{c}\text { Spring } \\
(24.2 \%, n=29)\end{array}$ & $\begin{array}{c}\text { Summer } \\
(40.8 \%, n=49)\end{array}$ & $\begin{array}{c}\text { Fall } \\
(26.7 \%, n=32)\end{array}$ & $\begin{array}{c}\text { Winter } \\
(8.3 \%, n=10)\end{array}$ \\
\hline TIgE & 57.5 & 51.7 & 63.3 & 50.0 & 60.0 \\
\hline D. farinae & 36.7 & 27.6 & 46.9 & 31.3 & 30.0 \\
\hline D. pteronyssinus & 34.2 & 17.2 & 44.9 & 34.4 & 30.0 \\
\hline Tyrophagus putr. & 17.5 & 6.9 & 22.4 & 21.9 & 10.0 \\
\hline Alternaria & 15.8 & 3.4 & 24.5 & 12.5 & 20.0 \\
\hline House dust & 14.2 & 17.2 & 16.3 & 6.3 & 20.0 \\
\hline Mugwort & 11.7 & 3.4 & 6.1 & 31.3 & 0.0 \\
\hline Cat & 10.8 & 3.4 & 14.3 & 9.4 & 20.0 \\
\hline Ragweed & 9.2 & 3.4 & 8.2 & 15.6 & 10.0 \\
\hline Oxeye-daisy & 8.3 & 0.0 & 6.1 & 15.6 & 20.0 \\
\hline Japanese hop & 8.3 & 3.4 & 6.1 & 15.6 & 10.0 \\
\hline Birch-Alder mix & 8.3 & 6.9 & 6.1 & 12.5 & 10.0 \\
\hline Rye pollen & 7.5 & 10.3 & 4.1 & 9.4 & 10.0 \\
\hline Dandelion & 6.7 & 0.0 & 4.1 & 15.6 & 10.0 \\
\hline Acarus siro & 5.8 & 13.8 & 4.1 & 0.0 & 10.0 \\
\hline Milk & 5.0 & 6.9 & 6.1 & 3.1 & 0.0 \\
\hline Cedar, Japan & 5.0 & 3.4 & 8.2 & 3.1 & 0.0 \\
\hline Cladosporium & 5.0 & 0.0 & 4.1 & 6.3 & 20.0 \\
\hline Russian Thistle & 4.2 & 0.0 & 6.1 & 6.3 & 0.0 \\
\hline Egg white & 4.2 & 0.0 & 2.0 & 9.4 & 10.0 \\
\hline Cockroach & 3.3 & 0.0 & 6.1 & 3.1 & 0.0 \\
\hline Peach & 3.3 & 3.4 & 4.1 & 0.0 & 10.0 \\
\hline Mackerel & 3.3 & 0.0 & 2.0 & 9.4 & 0.0 \\
\hline Sycamore mix & 3.3 & 0.0 & 4.1 & 3.1 & 10.0 \\
\hline Pigweed & 3.3 & 0.0 & 6.1 & 3.1 & 0.0 \\
\hline Bermuda grass & 2.5 & 0.0 & 2.0 & 3.1 & 10.0 \\
\hline Sweet vernal grass & 2.5 & 3.4 & 2.0 & 0.0 & 10.0 \\
\hline Dog & 2.5 & 6.9 & 2.0 & 0.0 & 0.0 \\
\hline Orchard grass & 2.5 & 3.4 & 4.1 & 3.1 & 0.0 \\
\hline Hazelnut & 2.5 & 3.4 & 0.0 & 3.1 & 10.0 \\
\hline Acacia & 2.5 & 0.0 & 2.0 & 3.1 & 10.0 \\
\hline Sallow willow & 2.5 & 3.4 & 2.0 & 0.0 & 10.0 \\
\hline CCD mix & 2.5 & 3.4 & 2.0 & 3.1 & 0.0 \\
\hline Reed & 2.5 & 3.4 & 2.0 & 0.0 & 10.0 \\
\hline Timothy grass & 2.5 & 3.4 & 4.1 & 3.1 & 0.0 \\
\hline Oak, White & 2.5 & 6.9 & 0.0 & 0.0 & 10.0 \\
\hline Crab & 1.7 & 0.0 & 2.0 & 3.1 & 0.0 \\
\hline Honey bee & 1.7 & 0.0 & 2.0 & 0.0 & 10.0 \\
\hline Potato & 1.7 & 0.0 & 2.0 & 0.0 & 10.0 \\
\hline Soybean & 0.8 & 0.0 & 2.0 & 0.0 & 0.0 \\
\hline Pine & 0.8 & 0.0 & 0.0 & 0.0 & 10.0 \\
\hline Poplar mix & 0.8 & 0.0 & 0.0 & 0.0 & 10.0 \\
\hline
\end{tabular}


Table 1. Cont.

\begin{tabular}{|c|c|c|c|c|c|}
\hline Allergen & $\begin{array}{c}\text { Total } \\
(100 \%, n=120)\end{array}$ & $\begin{array}{c}\text { Spring } \\
(24.2 \%, n=29)\end{array}$ & $\begin{array}{c}\text { Summer } \\
(40.8 \%, n=49)\end{array}$ & $\begin{array}{c}\text { Fall } \\
(26.7 \%, n=32)\end{array}$ & $\begin{array}{c}\text { Winter } \\
(8.3 \%, n=10)\end{array}$ \\
\hline Pork & 0.8 & 3.4 & 0.0 & 0.0 & 0.0 \\
\hline Aspergillus & 0.8 & 0.0 & 0.0 & 3.1 & 0.0 \\
\hline Cucumber & 0.8 & 0.0 & 2.0 & 0.0 & 0.0 \\
\hline Wheat flour & 0.8 & 0.0 & 2.0 & 0.0 & 0.0 \\
\hline Penicillium & 0.8 & 0.0 & 2.0 & 0.0 & 0.0 \\
\hline Latex & 0.8 & 0.0 & 2.0 & 0.0 & 0.0 \\
\hline Cacao & 0.8 & 0.0 & 2.0 & 0.0 & 0.0 \\
\hline Pupa & 0.8 & 0.0 & 0.0 & 3.1 & 0.0 \\
\hline Mango & 0.8 & 0.0 & 2.0 & 0.0 & 0.0 \\
\hline Banana & 0.0 & 0.0 & 0.0 & 0.0 & 0.0 \\
\hline Raw chestnut & 0.0 & 0.0 & 0.0 & 0.0 & 0.0 \\
\hline Buckwheat meal & 0.0 & 0.0 & 0.0 & 0.0 & 0.0 \\
\hline Candida albicans & 0.0 & 0.0 & 0.0 & 0.0 & 0.0 \\
\hline Guinea pig & 0.0 & 0.0 & 0.0 & 0.0 & 0.0 \\
\hline Peanut & 0.0 & 0.0 & 0.0 & 0.0 & 0.0 \\
\hline Sesame & 0.0 & 0.0 & 0.0 & 0.0 & 0.0 \\
\hline
\end{tabular}

IgE, immunoglobulin E; TIgE, serum total immunoglobulin E; D. farinae, Dermatophagoides farinae; D. pteronyssinus, Dermatophagoides pteronyssinus; Tyrophagus putr., Tyrophagus putrescentiae; CCD, Cross-reactive carbohydrate determinant.

\subsection{Subgroup Analysis of MAST-Immunoblot Assay}

Table 2 shows the comparison results between subgroups according to the detection of TIgE and SIgE. Sixty-nine patients (57.5\%) and 83 patients $(69.2 \%)$ were positive for TIgE and SIgE, respectively, and 59 patients $(49.2 \%)$ were positive for both TIgE and SIgE. Ninety-three patients (77.5\%) showed either TIgE or SIgE positivity, and neither was detected in 27 patients $(22.5 \%)$. There was a significant difference between subgroups with regard to the sex ratio $(p=0.002)$, but not age $(p=0.154)$ (Table 2). There was a significant difference in the sex ratio between Groups 1 and $4(p=0.001)$, and between Groups 3 and $4(p=0.030)$. Although there was no significant difference regarding age, Group 1 was younger than the rest of the groups. Figure 2 shows the results for seasonal distribution of allergen sensitizations.

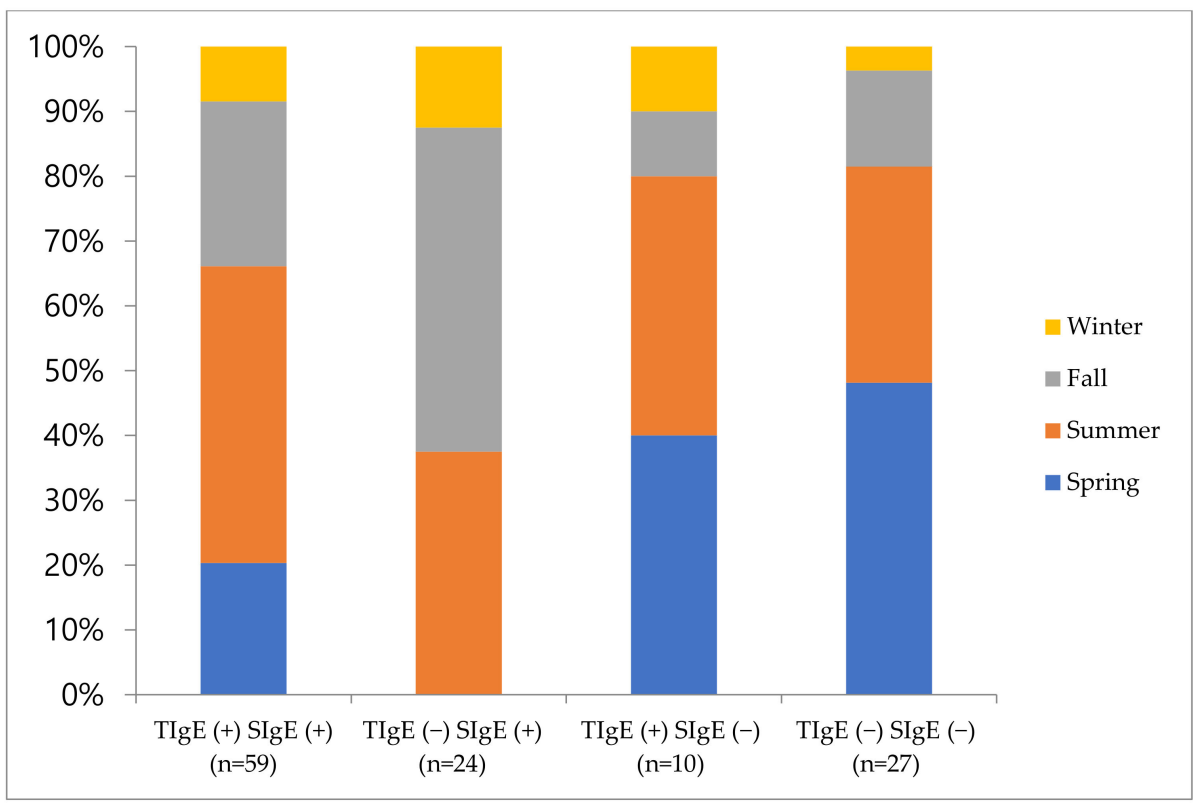

Figure 2. Seasonal distribution of each subgroup according to the detection of serum total immunoglobulin E and serum specific immunoglobulin E. TIgE, serum total immunoglobulin E; SigE, serum specific immunoglobulin E. 
Table 2. Comparison of the test results between subgroups according to the detection of TIgE and SIgE.

\begin{tabular}{cccc}
\hline & Number of Patients (\%) & Age (Years) & M:F \\
\hline Group 1; TIgE (+) SIgE (+) & $59(49.2)$ & $33.6 \pm 18.2$ & $22: 37$ \\
Group 2; TIgE (-) SIgE (+) & $24(20.0)$ & $34.2 \pm 16.3$ & $4: 20$ \\
Group 3; TIgE (+) SIgE (-) & $10(8.3)$ & $42.1 \pm 16.0$ & $5: 5$ \\
Group 4; TIgE (-) SIgE (-) & $27(22.5)$ & $39.1 \pm 17.2$ & $1: 26$ \\
$p$ value & & 0.154 & 0.002 \\
\hline MAST, multiple allergen simultaneous test; TigE, serum total immunoglobulin E; SigE, serum specific im-
\end{tabular}
munoglobulin E.

\subsection{Effect of Sex and Age on MAST-Immunoblot Assay}

Positive detection rates for TIgE and SIgE were higher in men than in women (TIgE: $84.4 \%$ for men vs. $47.7 \%$ for women, and SIgE: $81.2 \%$ for men vs. $64.8 \%$ for women); however, only the differences in TIgE were statistically significant $(p<0.001)$ (Table 3). Although there was no statistically significant difference in SIgE, men had a higher detection rate $(p=0.084)$. In addition, $96.9 \%$ of men were positive for either TIgE or SIgE, showing a significant difference compared to women $(70.5 \%)(p=0.001)$ (Table 3). According to the subgroup analysis with regard to age, positive detection rates for $\operatorname{TIgE}$ and $\operatorname{SIgE}$ were higher in the young group than in the old group (TIgE: $64.3 \%$ for young group vs. $48.0 \%$ for old group and SIgE: $77.1 \%$ for young group vs. $58.0 \%$ for old group), but only the differences in SIgE were statistically significant $(p=0.025)$ (Table 3$)$. Although there was no statistical significance in TIgE, the young group had a high detection rate $(p=0.075)$ (Table 3$)$.

Table 3. Comparison of the test results between sex and age groups.

\begin{tabular}{ccccc}
\hline Sex (Male vs. Female) & Total $(\boldsymbol{n = 1 2 0})$ & Male $(\boldsymbol{n = 3 2})$ & Female $(\boldsymbol{n = 8 8 )}$ & $\boldsymbol{p}$ Value \\
\hline Age & $35.7 \pm 17.5$ & $33.3 \pm 16.9$ & $36.55 \pm 17.7$ & 0.345 \\
TIgE(+):TIge $(-)$ & $69: 51(57.5 \%: 42.5 \%)$ & $27: 5(84.4 \%: 15.6 \%)$ & $42: 46(47.7 \%: 52.3 \%)$ & $<0.001$ \\
SIgE(+):SIge $(-)$ & $83: 37(69.2 \%: 30.8 \%)$ & $26: 6(81.2 \%: 18.8 \%)$ & $57: 31(64.8 \%: 35.2 \%)$ & 0.084 \\
AIgE(+):AIge(-) & $93: 27(77.5 \%: 22.5 \%)$ & $31: 1(96.9 \%: 3.1 \%)$ & $62: 26(70.5 \%: 29.5 \%)$ & 0.001 \\
\hline Age (young vs. old) & Total $(\boldsymbol{n}=\mathbf{1 2 0})$ & Young group $(\boldsymbol{n}=\mathbf{7 0})$ & Old group $(\boldsymbol{n}=\mathbf{5 0})$ & $\boldsymbol{p}$ Value \\
\hline Sex (male:female) & $32: 88$ & $20: 50$ & $12: 38$ & 0.577 \\
TIgE(+): TIge(-) & $69: 51(57.5 \%: 42.5 \%)$ & $45: 25(64.3 \%: 35.7 \%)$ & $24: 26(48.0 \%: 52.0 \%)$ & 0.075 \\
SIgE(+): SIge(-) & $83: 37(69.2 \%: 30.8 \%)$ & $54: 16(77.1 \%: 22.9 \%)$ & $29: 21(58.0 \%: 42.0 \%)$ & 0.025 \\
AIgE(+):AIge $(-)$ & $93: 27(77.5 \%: 22.5 \%)$ & $58: 12(82.9 \%: 17.1 \%)$ & $35: 15(70.0 \%: 30.0 \%)$ & 0.096 \\
\hline
\end{tabular}

TIgE, serum total immunoglobulin E; SIgE, serum specific immunoglobulin E; $\mathrm{AIgE}(+)$, positive for at least one of $\mathrm{TIgE}$ and $\operatorname{SIgE}$; $\mathrm{AIgE}(-)$, negative for both TIgE and SIgE.

\section{Discussion}

Identification of the sensitizing allergen is important in diagnosis, avoidance, and allergy treatment, especially before initiating specific immunotherapy [22]. The effect of immunotherapy on relieving ocular symptoms has been shown in previous studies $[23,24]$. In particular, even several years after the completion of immunotherapy, its efficacy for ocular symptoms remains [25]. The widely used method for detecting the sensitizing allergen is the SPT, which has both high sensitivity and good reproducibility. However, individuals with a high risk for anaphylaxis are contraindicated to undergo SPT. Medications may affect the results of SPT when taken concurrently, including antihistamines, tricyclic antidepressants, omalizumab, and topical steroids in the test area [11-13].

Various test methods have been developed to overcome these limitations, among which, the detection of serum IgE, which acts as a key mediator in the occurrence of allergy, is the mainstream [26]. The radioallergosorbent test (RAST), FAST, and MAST have been developed for detecting IgE in serum. MAST is mainly used because of its advantages such as being free from isotope, faster test time, low cost, and ability to simultaneously test for 
multiple allergens. Recently, the MAST-immunoblot assay was developed; which reduces the testing time from $48 \mathrm{~h}$ to less than $3 \mathrm{~h}$ and involves a simplified testing procedure compared to the previous MAST-chemiluminescence assay [17]. Moreover, it requires a lesser amount of blood sample. The MAST-immunoblot assay has shown similar or better allergen detection rates compared to SPT or other in vitro IgE methods [18].

In this study, house dust mites, such as D. farinae (36.7\%) and D. pteronyssinus (34.2\%), were the most detected allergens. This is consistent with the results of a large-scale study of Korean patients with allergic disease [18,27]. In addition, house dust mite showed the highest detection rates regardless of the season, which is in line with the fact that the most common cause of perennial allergic conjunctivitis is house dust mite [28]. There was a seasonal variation when the detection rate is was analyzed by season, indicating that seasonal exposure to different allergens occurred, leading to the development of seasonal allergic conjunctivitis or an exacerbation of perennial allergic conjunctivitis. In spring, the positive detection rate of $A$. siro $(13.8 \%)$ was higher than that in other seasons, possibly due to the peak of the $A$. siro population in spring (especially April) [29]. In the life cycle of T. putrescentiae, a high temperature and humid environment are essential; therefore, the detection rate is expected to be high in summer and autumn $(22.4 \%$ and $21.9 \%$, respectively, in our study). The high detection rate of Alternaria $(24.5 \%)$ in summer can be explained by similar reasons. Mugwort (31.3\%), ragweed (15.6\%), Japanese hop (15.6\%), and dandelion $(15.6 \%)$ had a higher positivity rate in fall than in other seasons, possibly due to the abundance of pollen in the air during fall [30]. In winter, the positivity for house dust and cat allergen was high, which can be explained by the relatively lower ventilation owing to changes in climate. However, the high detection rate of Alternaria and Cladosporium was not in line with their life cycles.

The percentage of individuals who were positive for TIgE or SIgE for at least one allergen was $57.5 \%$ and $69.2 \%$, respectively. This result is similar to the results of previous studies using the MAST-immunoblot assay, but lower than the results of SPT [31,32]. In vitro methods measure circulating IgE in serum; however, in practice, most IgE is attached to the mast cells of the tissue; therefore, the IgE level can be underestimated by in vitro methods (lower sensitivity, false negativity) $[5,33]$. Conversely, in in vivo methods, the positive detection rate increases due to non-IgE-mediated triggers or alternative mechanisms (lower specificity, false positivity) [5,34]. There were $8.3 \%(n=10)$ of patients with increased TIgE levels, although no SIgE was detected. Some interpret this as involvement of other factors that increase the serum IgE levels except allergy, such as parasitic infection, neoplastic diseases, and immune deficiencies [35]. However, we excluded patients with these diseases from the study, and regardless of sensitization to SIgE, an increase in TIgE concentration was found to be associated with the onset and worsening of allergy symptoms [36]. Both TIgE and SIgE were negative in $22.5 \%$ of patients. It is unclear how many of these patients may have had local allergic conjunctivitis which cannot be detected through SIgE. In addition, considering that $0.7 \mathrm{IU} / \mathrm{mL}$ was used as a cut-off for positive detection of SIgE, different results may be obtained if the cut-off value is changed to $0.35 \mathrm{IU} / \mathrm{mL}$. Moreover, underestimated IgE levels in in vitro tests may also result in differences in the test results [5,33]. When seasonal distribution between subgroups was analyzed, the proportions of positive cases in each season were different. In this study, there was a difference in the TIgE or SIgE positivity according to sex. However, it was significant only for TIgE. In a prior study, the National Health and Nutrition Examination Survey 2005-2006 of the US population, men were more likely to exhibit positive SIgE tests and elevated levels of SIgE than women [37]. Some studies have suggested that differences in the production of IgE may be associated with differences in genetic, hormonal, and environmental factors involved in IgE control [38,39]. Although no statistical significance was observed in this study, it was found that men had a tendency of showing a higher SIgE positivity rate than women. Therefore, this needs to be confirmed in a larger study.

With regard to the positivity rate of TIgE or SIgE, there was a difference according to age. The SIgE positivity rate was significantly higher in the young group than in the old 
group; however, TIgE did not show any significant difference. Several studies have shown that serum IgE level is higher in younger than in older individuals $[37,40,41]$. The decline in the prevalence of IgE sensitization in older individuals may be attributed to gradual deterioration of the immune system, called "immunosenescence" [42,43]. The secretion of IgE depends on the interaction between B and T lymphocytes and is reduced by the naturally occurring involution of the thymus, which plays a key role in the development of T lymphocytes [44]. In an animal study, the transplantation of thymocytes in young mice did not cause a change in IgE secretion, whereas in aged mice, IgE secretion was triggered to a level similar to that in young mice [45]. A large-scale study reported that SIgE levels decreased with aging and that TIgE levels were maintained despite aging. Furthermore, TIgE levels gradually increased after 60 year-old and peaked in the oldest subgroup of 85 years or older, which is attributed to the impaired regulatory function with aging [21].

This study has several limitations. First, the number of patients included in the study was relatively small; however, it was challenging to identify patients with isolated allergic conjunctivitis who did not have associated allergic rhinitis, asthma, or dermatitis. Second, other factors known to influence the IgE level (socioeconomic state, education level, and residual area) were not analyzed. Third, because the study was performed in a single region, the results may not reflect local differences. Finally, since SPT was not concurrently performed in this study, the correlation with allergens detected in the MAST-immunoblot assay could not be analyzed.

\section{Conclusions}

When detecting the sensitizing allergen in patients with isolated allergic conjunctivitis using the MAST-immunoblot assay, allergen-triggered sensitization differed according to the season when the eye symptoms were exacerbated. Furthermore, IgE detection differed according to sex and age. This is the first study to perform the MAST-immunoblot assay by selecting only patients with no other allergic symptoms except ocular symptoms, while targeting only IgE-mediated allergic conjunctivitis. Since the results differed according to sex and age, the MAST results should be interpreted carefully in patients with isolated allergic conjunctivitis. We expect that our study results can be used by clinicians when predicting the pattern of allergens according to seasons and interpreting test results according to age and sex.

Author Contributions: Conceptualization, J.Y.H., H.L., J.L.C., Y.J.K., J.Y.K. and H.T.; methodology, J.Y.H., H.L., J.L.C., Y.J.K., J.Y.K. and H.T.; validation, H.L., J.L.C. and H.T.; formal analysis, J.Y.H., H.L., J.L.C., Y.J.K., J.Y.K. and H.T.; investigation, J.Y.H., H.L., J.L.C., Y.J.K., J.Y.K. and H.T.; data curation, J.Y.H., H.L., J.L.C., J.Y.K. and H.T.; writing-original draft preparation, J.Y.H., H.L., J.L.C., Y.J.K., J.Y.K. and H.T.; writing - review and editing, J.Y.H., H.L., J.L.C., Y.J.K., J.Y.K. and H.T.; supervision, H.L., J.Y.K. and H.T.; project administration, H.L., J.L.C., and H.T.; funding acquisition, H.L., J.Y.K. and H.T. All authors have read and agreed to the published version of the manuscript.

Funding: This research was supported by Research and Business Development Program through the Korea Institute for Advancement of Technology(KIAT) funded by the Ministry of Trade, Industry and Energy(MOTIE) (grant number: P0014063), by the Korea Medical Device Development Fund grant funded by the Korea government (the Ministry of Science and ICT, the Ministry of Trade, Industry and Energy, the Ministry of Health \& Welfare, Republic of Korea, the Ministry of Food and Drug Safety) (Project Number: 2020M3E5D8104338, 2020M3E5D8106706), and by a grant from the Asan Institute for Life Sciences, Asan Medical Center, Seoul, Korea (2020IP0045-3, 2019IP0813).

Institutional Review Board Statement: The study was conducted according to the guidelines of the Declaration of Helsinki, and approved by the Institutional Review Board of the Asan Medical Center and the University of Ulsan College of Medicine, Seoul, South Korea (2020-1858).

Informed Consent Statement: Patient consent was waived due to the retrospective nature.

Data Availability Statement: Data are available upon request from the authors. 
Conflicts of Interest: The authors declare no conflict of interest. The funders had no role in the design of the study; in the collection, analyses, or interpretation of data; in the writing of the manuscript, or in the decision to publish the results.

\section{References}

1. Tang, A.W. A practical guide to anaphylaxis. Am. Fam. Physician 2003, 68, 1325-1332. [PubMed]

2. Petricek, I.; Prost, M.; Popova, A. The differential diagnosis of red eye: A survey of medical practitioners from eastern europe and the middle east. Ophthalmologica 2006, 220, 229-237. [CrossRef] [PubMed]

3. Bielory, L. Allergic conjunctivitis and the impact of allergic rhinitis. Curr. Allergy Asthma Rep. 2010, 10, 122-134. [CrossRef]

4. Pitt, A.D.; Smith, A.F.; Lindsell, L.; Voon, L.W.; Rose, P.W.; Bron, A.J. Economic and quality-of-life impact of seasonal allergic conjunctivitis in oxfordshire. Ophthalmic Epidemiol. 2004, 11, 17-33. [CrossRef]

5. Platt, M.P.; Wulu, J.A. Rational Approach to Allergy Testing. Otolaryngol. Clin. N. Am. 2017, 50, 1103-1110. [CrossRef]

6. Leonardi, A.; De Dominicis, C.; Motterle, L. Immunopathogenesis of ocular allergy: A schematic approach to different clinical entities. Curr. Opin. Allergy Clin. Immunol. 2007, 7, 429-435. [CrossRef]

7. Leonardi, A.; Borghesan, F.; Faggian, D.; Depaoli, M.; Secchi, A.G.; Plebani, M. Tear and serum soluble leukocyte activation markers in conjunctival allergic diseases. Am. J. Ophthalmol. 2000, 129, 151-158. [CrossRef]

8. Sampath, V.; Tupa, D.; Graham, M.T.; Chatila, T.A.; Spergel, J.M.; Nadeau, K.C. Deciphering the black box of food allergy mechanisms. Ann. Allergy Asthma Immunol. 2017, 118, 21-27. [CrossRef]

9. Kim, Y.H.; Yu, B.J.; Kim, W.J.; Kim, J.E.; Lee, G.H.; Lee, K.A.; Cho, J.H. Correlation between skin prick test and mast-immunoblot results in patients with chronic rhinitis. Asian Pac. J. Allergy Immunol. 2013, 31, 20-25.

10. Park, K.H.; Lee, J.; Sim, D.W.; Lee, S.C. Comparison of Singleplex Specific IgE Detection Immunoassays: ImmunoCAP Phadia 250 and Immulite 2000 3gAllergy. Ann. Lab. Med. 2018, 38, 23-31. [CrossRef] [PubMed]

11. Simons, F.E.; Johnston, L.; Gu, X.; Simons, K.J. Suppression of the early and late cutaneous allergic responses using fexofenadine and montelukast. Ann. Allergy Asthma Immunol. 2001, 86, 44-50. [CrossRef]

12. Gradman, J.; Wolthers, O.D. Suppressive effects of topical mometasone furoate and tacrolimus on skin prick testing in children. Pediatr. Dermatol. 2008, 25, 269-270. [CrossRef] [PubMed]

13. Corren, J.; Shapiro, G.; Reimann, J.; Deniz, Y.; Wong, D.; Adelman, D.; Togias, A. Allergen skin tests and free ige levels during reduction and cessation of omalizumab therapy. J. Allergy Clin. Immunol. 2008, 121, 506-511. [CrossRef]

14. Shah, K.M.; Rank, M.A.; Dave, S.A.; Oslie, C.L.; Butterfield, J.H. Predicting which medication classes interfere with allergy skin testing. Allergy Asthma Proc. 2010, 31, 477-482. [CrossRef]

15. Birch, K.; Pearson-Shaver, A.L. Allergy Testing; StatPearls Publishing: Treasure Island, FL, USA, 2020.

16. Sadreddini, H.A.; Starkey, E.S. Drug allergy: Diagnosis and management of drug allergy in adults, children and young people; a look at nice guidance. Arch. Dis. Child. Educ. Pract. Ed. 2016, 101, 239-242. [CrossRef]

17. Jang, W.R.; Nahm, C.H.; Kim, J.H.; Lim, D.H.; Jang, T.Y.; Moon, Y.S.; Kim, J.J. Allergen specific ige measurement with polycheck allergy: Comparison of three multiple allergen simultaneous tests. Korean J. Lab. Med. 2009, 29, 465-472. [CrossRef] [PubMed]

18. Lee, J.H.; Park, K.H.; Kim, H.S.; Kim, K.W.; Sohn, M.H.; Kim, C.H.; Lee, J.S.; Hong, C.S.; Park, J.W. Specific ige measurement using advansure(r) system: Comparison of detection performance with immunocap(r) system in korean allergy patients. Clin. Chim. Acta 2012, 413, 914-919. [CrossRef]

19. Jiang, X.D.; Li, G.Y.; Dong, Z.; Zhu, D.D. Correlation analysis of two serum-specific immunoglobulin e test systems and skin-prick test in allergic rhinitis patients from northeast china. Am. J. Rhinol. Allergy 2011, 25, 116-119. [CrossRef]

20. Miyazaki, D.; Takamura, E.; Uchio, E.; Ebihara, N.; Ohno, S.; Ohashi, Y.; Okamoto, S.; Satake, Y.; Shoji, J.; Namba, K.; et al. Japanese guidelines for allergic conjunctival diseases 2020. Allergol. Int. Off. J. Jpn. Soc. Allergol. 2020, 69, 346-355. [CrossRef]

21. De Amici, M.; Ciprandi, G. The age impact on serum total and allergen-specific ige. Allergy Asthma Immunol. Res. 2013, 5, 170-174. [CrossRef]

22. Roberts, G.; Pfaar, O.; Akdis, C.A.; Ansotegui, I.J.; Durham, S.R.; Gerth van Wijk, R.; Halken, S.; Larenas-Linnemann, D.; Pawankar, R.; Pitsios, C.; et al. EAACI Guidelines on Allergen Immunotherapy: Allergic rhinoconjunctivitis. Allergy 2018, 73, 765-798. [CrossRef]

23. Nolte, H.; Maloney, J.; Nelson, H.S.; Bernstein, D.I.; Lu, S.; Li, Z.; Kaur, A.; Zieglmayer, P.; Zieglmayer, R.; Lemell, P.; et al. Onset and dose-related efficacy of house dust mite sublingual immunotherapy tablets in an environmental exposure chamber. J. Allergy Clin. Immunol. 2015, 135, 1494-1501 e1496. [CrossRef]

24. Calderon, M.A.; Penagos, M.; Sheikh, A.; Canonica, G.W.; Durham, S. Sublingual immunotherapy for treating allergic conjunctivitis. Cochrane Database Syst. Rev. 2011. [CrossRef] [PubMed]

25. Niggemann, B.; Jacobsen, L.; Dreborg, S.; Ferdousi, H.A.; Halken, S.; Host, A.; Koivikko, A.; Koller, D.; Norberg, L.A.; Urbanek, R.; et al. Five-year follow-up on the pat study: Specific immunotherapy and long-term prevention of asthma in children. Allergy 2006, 61, 855-859. [CrossRef]

26. Chinthrajah, R.S.; Hernandez, J.D.; Boyd, S.D.; Galli, S.J.; Nadeau, K.C. Molecular and cellular mechanisms of food allergy and food tolerance. J. Allergy Clin. Immunol. 2016, 137, 984-997. [CrossRef] [PubMed]

27. Ohn, J.; Paik, S.H.; Doh, E.J.; Park, H.S.; Yoon, H.S.; Cho, S. Allergen sensitization pattern by sex: A cluster analysis in korea. Ann. Dermatol. 2017, 29, 735-741. [CrossRef] 
28. El-Nahas, H.A.; El-Beshbishi, S.N.; Azab, M.S.; Zaalouk, T.; Elsheikha, H.M.; Saleh, A.B.; El-Shazly, A.M. Diagnostic criteria for house dust mites sensitized allergic patients. J. Egypt Soc. Parasitol. 2007, 37, 1113-1124. [PubMed]

29. Abdel-Salam, B.K. Seasonal population of acarus siro mites and effects of their faeces on allergenic immunological disorder modulated by garlic in albino rat. Allergol. Immunopathol. 2012, 40, 144-151. [CrossRef] [PubMed]

30. Oh, J.W.; Lee, H.B.; Kang, I.J.; Kim, S.W.; Park, K.S.; Kook, M.H.; Kim, B.S.; Baek, H.S.; Kim, J.H.; Kim, J.K.; et al. The revised edition of korean calendar for allergenic pollens. Allergy Asthma Immunol. Res. 2012, 4, 5-11. [CrossRef]

31. Jung, S.W.; Oh, E.J.; Lee, J.; Kim, Y.; Kim, S.Y.; Kim, Y.; Park, Y.J. Usefulness of total ige in predicting positive allergen specific ige tests in korean subjects. Korean J. Lab. Med. 2010, 30, 660-667. [CrossRef]

32. Zhang, L.; Han, B.; Zhang, Z.; Liu, A.; Liu, G.; Du, Z.; Yao, Y.; Qi, Q. Skin prick test of inhalative allergens for patients with allergic rhinitis in yichang. Lin Chung Er Bi Yan Hou Tou Jing Wai Ke Za Zhi 2014, 28, 98-101. [PubMed]

33. Emanuel, I.A. In vitro testing for allergy diagnosis. Otolaryngol. Clin. N. Am. 2003, 36, 879-893. [CrossRef]

34. Ownby, D.R.; Bailey, J. Comparison of mast with radioallergosorbent and skin tests for diagnosis of allergy in children. Am. J. Dis. Child. 1986, 140, 45-48. [CrossRef]

35. Ahmed, I.; Nasreen, S. Frequency of raised serum ige level in childhood atopic dermatitis. J. Pak. Med. Assoc. 2007, 57, 431-434. [PubMed]

36. Sunyer, J.; Anto, J.M.; Castellsague, J.; Soriano, J.B.; Roca, J. Total serum ige is associated with asthma independently of specific ige levels. The spanish group of the european study of asthma. Eur. Respir. J. 1996, 9, 1880-1884. [CrossRef] [PubMed]

37. Salo, P.M.; Arbes, S.J., Jr.; Jaramillo, R.; Calatroni, A.; Weir, C.H.; Sever, M.L.; Hoppin, J.A.; Rose, K.M.; Liu, A.H.; Gergen, P.J.; et al. Prevalence of allergic sensitization in the united states: Results from the national health and nutrition examination survey (nhanes) 2005-2006. J. Allergy Clin. Immunol. 2014, 134, 350-359. [CrossRef]

38. Johnson, C.C.; Peterson, E.L.; Ownby, D.R. Gender differences in total and allergen-specific immunoglobulin e (ige) concentrations in a population-based cohort from birth to age four years. Am. J. Epidemiol. 1998, 147, 1145-1152. [CrossRef] [PubMed]

39. Uekert, S.J.; Akan, G.; Evans, M.D.; Li, Z.; Roberg, K.; Tisler, C.; Dasilva, D.; Anderson, E.; Gangnon, R.; Allen, D.B.; et al. Sex-related differences in immune development and the expression of atopy in early childhood. J. Allergy Clin. Immunol. 2006, 118, 1375-1381. [CrossRef]

40. Warm, K.; Backman, H.; Lindberg, A.; Lundback, B.; Ronmark, E. Low incidence and high remission of allergic sensitization among adults. J. Allergy Clin. Immunol. 2012, 129, 136-142. [CrossRef]

41. Nakazawa, T.; Houjyo, S.; Dobashi, K.; Sato, K. Influence of aging and sex on specific ige antibody production. Intern Med. 1994, 33, 396-401. [CrossRef]

42. Gomez, C.R.; Boehmer, E.D.; Kovacs, E.J. The aging innate immune system. Curr. Opin. Immunol. 2005, 17, 457-462. [CrossRef] [PubMed]

43. Sansoni, P.; Vescovini, R.; Fagnoni, F.; Biasini, C.; Zanni, F.; Zanlari, L.; Telera, A.; Lucchini, G.; Passeri, G.; Monti, D.; et al. The immune system in extreme longevity. Exp. Gerontol. 2008, 43, 61-65. [CrossRef] [PubMed]

44. Geha, R.S.; Jabara, H.H.; Brodeur, S.R. The regulation of immunoglobulin e class-switch recombination. Nat. Rev. Immunol. 2003, 3, 721-732. [CrossRef] [PubMed]

45. Fujiwara, M.; Kishimoto, S. Ige antibody formation and aging. I. Age-related changes in ige antibody formation and avidity for the dnp-determinant in mice. J. Immunol. 1979, 123, 263-268. [PubMed] 